Check for updates

Cite this: RSC Adv., 2018, 8, 38945

Received 22nd May 2018

Accepted 31st July 2018

DOI: $10.1039 / \mathrm{c} 8 \mathrm{ra04350g}$

rsc.li/rsc-advances

\section{Hydrothermal synthesis of flower-like molybdenum disulfide microspheres and their application in electrochemical supercapacitors}

\author{
Fangping Wang, (D)* Guifang Li, Jinfeng Zheng, Jing Ma, Caixia Yang \\ and Qizhao Wang (DD
}

Three-dimensional flower-like molybdenum disulfide microspheres composed of nanosheets were prepared by a hydrothermal method using ammonium molybdate as the molybdenum source and thiourea as the sulfur source. Structural and morphological characterizations were performed by $X$-ray diffraction (XRD), scanning electron microscopy (SEM), transmission electron microscopy (TEM), energydispersive $X$-ray (EDX) spectroscopy and X-ray photoelectron spectroscopy (XPS). The electrochemical properties of $\mathrm{MoS}_{2}$ electrode were studied by performing cyclic voltammetry (CV), galvanostatic chargedischarge analysis and electrochemical impedance spectroscopy (EIS). When used as an electrode material for supercapacitor, the hybrid $\mathrm{MoS}_{2}$ showed a high specific capacity of $518.7 \mathrm{~F} \mathrm{~g}^{-1}$ at a current density of $1 \mathrm{~A} \mathrm{~g}^{-1}$ and $275 \mathrm{~F} \mathrm{~g}^{-1}$ at a high discharge current density of $10 \mathrm{~A} \mathrm{~g}^{-1}$. In addition, a symmetric supercapacitor composed of $\mathrm{MoS}_{2}$ as positive and negative electrodes was prepared, which exhibited a high energy density of $12.46 \mathrm{~W} \mathrm{~h} \mathrm{~kg}^{-1}$ at a power density of $70 \mathrm{~W} \mathrm{~kg}^{-1}$ and still maintains an impressive energy density of $6.42 \mathrm{~W} \mathrm{~h} \mathrm{~kg}^{-1}$ at a large power density of $7000 \mathrm{~W} \mathrm{~kg}^{-1}$. The outstanding performance of the $\mathrm{MoS}_{2}$ electrode material indicates its great potential for applications in high-performance energy storage systems.

\section{Introduction}

Supercapacitors, also known as electrochemical capacitors, have gathered growing interest of researchers in the era of miniaturization of devices. ${ }^{1,2}$ These present fascinating properties of higher energy density, higher power density, longer life, lower toxicity than batteries, and so on, compared with those of traditional capacitors. ${ }^{3-6}$ According to the charge-discharge mechanisms, SCs can be divided into electrical double-layer capacitors (EDLCs) and pseudocapacitors. ${ }^{7,8}$ Pseudocapacitance arises from reversible faradaic reactions of redox active materials, such as transition metal oxides, hydroxides, and sulfides. Among those materials, ruthenium oxide $\left(\mathrm{RuO}_{2}\right)$ has exhibited excellent pseudocapacitive performance, but the toxicity and high cost of $\mathrm{RuO}_{2}$ restrict its widespread commercial application. ${ }^{9,10}$ The low cost active material $\mathrm{MnO}_{2}$ can also achieve a high specific capacitance; however, $\mathrm{MnO}_{2}$-based pseudocapacitors suffer from poor electrical conductivity and cyclic stability. ${ }^{11}$ Application of nanometal sulfides in the energy storage devices, such as fuel cells, solar energy pools, lithiumion batteries, and supercapacitors, have aroused widespread

Key Laboratory of Eco-Environment-Related Polymer Materials, Ministry of Education of China, Key Laboratory of Gansu Polymer Materials, College of Chemistry and Chemical Engineering, Northwest Normal University, Lanzhou 730070, China. E-mail:wangfp@nwnu.edu.cn interest among researchers. At present, carbon materials (such as activated carbon), transition metal oxides (nickel oxide, etc.), and conductive polymers are often used as electrode materials for supercapacitors. ${ }^{12,13}$ However, the growing demand for energy storage devices has prompted researchers to develop new types of electrode materials. Therefore, the research of nanometer-scale metal sulfide as the material of supercapacitor electrode has become a new field. For example, cobalt sulfide (CoS, $\mathrm{CoS}_{2}$ ), nickel sulfide ( $\mathrm{NiS}, \mathrm{NiS}_{2}, \mathrm{Ni}_{3} \mathrm{~S}_{2}$ ), molybdenum sulfide $\left(\mathrm{MoS}_{2}\right)$, copper sulfide $\left(\mathrm{CuS}, \mathrm{Cu}_{2} \mathrm{~S}\right)$, and vanadium sulfide ( $\mathrm{VS}, \mathrm{VS}_{2}$ ) have been used as supercapacitors electrode materials. ${ }^{14-16}$ In particular, $\mathrm{MoS}_{2}$ has aroused interest among other transition metal sulfides due to its layered structure and inherent conductivity, ${ }^{17}$ and it is considered to be a suitable replacement for graphene and carbon nanotubes in energy storage applications. In addition, molybdenum-based materials (such as $\mathrm{MoO}_{3}, \mathrm{MoO}_{2}$, and $\mathrm{MoS}_{2}$ ) exhibit various valences and rich chemical properties, making them viable candidate materials for electrochemical applications. ${ }^{18}$

$\mathrm{MoS}_{2}$ is a transition metal sulfide with a layered structure, where a metal molybdenum layer is sandwiched between two sulfur layers; the layers are connected by weak van der Waals forces and the interlayer S-Mo-S atoms are strongly covalently linked. ${ }^{19-21} \mathrm{MoS}_{2}$ possesses unique physicochemical properties due to its unique atomic and electronic structure. It is mainly used in the solid lubricants, catalysts, supercapacitors and 
lithium-ion batteries. ${ }^{22-24}$ Among these, the research on the application of $\mathrm{MoS}_{2}$ as a supercapacitor electrode material is the most extensive. For example, Soon et al. ${ }^{25}$ found that the $\mathrm{MoS}_{2}$ nano-film presented an electric double layer capacitance behavior. Ma et al. $^{26}$ reported that nano-MoS $\mathrm{M}_{2}$ intercalated in polypyrrole could improve its capacitance performance. Cao et $a .^{27}$ fabricated micro-supercapacitors using coated $\mathrm{MoS}_{2}$ nanofilms, and showed that $\mathrm{MoS}_{2}$ has excellent electrochemical performance in aqueous electrolytes.

In particular, the structure of the electrode directly affects its electrochemical properties. Generally, the electrochemical electrode is 2-dimensional and suffers from inadequate contact with electrolyte and low surface-area-utilization efficiency. Numerous efforts have been made to design three-dimensional (3D) electrodes, such as $\mathrm{MoS}_{2} /$ mesoporous carbon spheres. Recently, there have been some reports related to $\mathrm{NiCo}_{2} \mathrm{~S}_{4}$ and graphene oxide composites applied in supercapacitors. Krishnamoorthy et al. ${ }^{15}$ reported $92.85 \mathrm{~F} \mathrm{~g}^{-1}$ specific capacitance of chemically prepared $\mathrm{MoS}_{2}$ nanostructure. Huang et al. ${ }^{28}$ reported polyaniline/ $\mathrm{MoS}_{2}$ composites as supercapacitor electrodes with the specific capacitance of $575 \mathrm{~F} \mathrm{~g}^{-1}$.

In this paper, the morphologically regular flower-like molybdenum disulfide microspheres were successfully synthesized by a hydrothermal method (Fig. 1). The as-prepared $\mathrm{MoS}_{2}$ was directly used as a supercapacitor electrode and exhibited high specific capacitance $\left(518.7 \mathrm{~F} \mathrm{~g}^{-1}\right.$ at current density of $1 \mathrm{~A} \mathrm{~g}^{-1}$ ) and excellent cycling performance (88.2\% retention after 2500 cycles). In addition, a high performance symmetric supercapacitor was successfully fabricated by using $\mathrm{MoS}_{2}$ as both positive electrode and negative electrode, which exhibited a high energy density of $12.46 \mathrm{~W} \mathrm{~h} \mathrm{~kg}^{-1}$ at power density of $70 \mathrm{~W} \mathrm{~kg}^{-1}$.

\section{Experimental section}

\subsection{Materials}

Ammonium molybdate $\left(\left(\mathrm{NH}_{4}\right)_{6} \mathrm{Mo}_{7} \mathrm{O}_{24} \cdot 4 \mathrm{H}_{2} \mathrm{O}\right)$ and thiourea $\left(\mathrm{CH}_{4} \mathrm{~N}_{2} \mathrm{~S}\right)$ were obtained from Tianjin Kaixin Chemical Industry Co. Ltd. All the chemical reagents were of analytical purity and used without any further purification.

\subsection{Synthesis of $\mathrm{MoS}_{2}$}

In a typical process, $0.8 \mathrm{~g}$ of ammonium molybdate and $5.12 \mathrm{~g}$ thiourea were dissolved into $80 \mathrm{~mL}$ deionized water and stirred until the solution was clear and transparent. The solution was transferred into $100 \mathrm{~mL}$ PTFE-lined stainless steel autoclave and heated at $200{ }^{\circ} \mathrm{C}$ for different time periods $(8 \mathrm{~h}, 16 \mathrm{~h}$, and 24 h). The obtained $\mathrm{MoS}_{2}$ was flushed with water and ethanol, in sequence, and then dried at $70{ }^{\circ} \mathrm{C}$ for $12 \mathrm{~h}$. The $\mathrm{MoS}_{2}$ electrode materials were denoted as $\mathrm{MoS}_{2}-8, \mathrm{MoS}_{2}-16$, and $\mathrm{MoS}_{2}-24$, according to the hydrothermal treatment time.

\subsection{Material characterization}

The morphology and microstructure of the samples were characterized by field-emission scanning electron microscopy (FESEM JSM-6701F, Japan), transmission electron microscopy (TEM; JEOL, JEM-2010, Japan), and X-ray diffraction (XRD, D/ Max-2400, Japan) with $\mathrm{Cu} \mathrm{K} \alpha$ radiation $(\lambda=1.5418 \AA)$ operating at $40 \mathrm{kV}, 100 \mathrm{~mA}$. X-ray photoelectron spectroscopy (XPS) spectra were recorded on a PHI 5702 spectrometer using a standard $\mathrm{Al} \mathrm{K} \alpha \mathrm{X}$-ray source of $300 \mathrm{~W}$ and an analyser pass energy of $29.35 \mathrm{eV}$.

\subsection{Electrode preparation and electrochemical characterization}

The electrochemical properties of the $\mathrm{MoS}_{2}$ nanostructures were investigated in $1 \mathrm{M} \mathrm{Na}_{2} \mathrm{SO}_{4}$ solution using a threeelectrode system in an electrochemical work station (CHI660E, Shanghai). Initially, $8 \mathrm{mg}$ of $\mathrm{MoS}_{2}-16$ was dispersed in $400 \mu \mathrm{L}$ of $0.5 \mathrm{wt} \%$ Nafion solution by ultrasonication to obtain a well dispersed suspension. Then, $6 \mu \mathrm{L}$ of the suspension was drop-casted onto the pre-treated glassy carbon electrode (GCE) and left to dry at room temperature. Saturated calomel electrode, platinum wire, and a loadable glassy carbon electrode were respectively the reference, the counter, and the working electrodes. ${ }^{29}$ Cyclic voltammetry (CV) in the range -0.3 to $0.5 \mathrm{~V}$ was performed at different scan rates. Galvanostatic charge-discharge curves were recorded in the potential range of -0.3 to $0.5 \mathrm{~V}$ at different constant current density. The cycle life tests were performed by galvanostatic charge-discharge measurements with a constant current density of $4 \mathrm{~A} \mathrm{~g}^{-1}$ for 2500 cycles. Electrochemical impedance spectroscopy (EIS) was performed in the frequency range of $0.01 \mathrm{~Hz}$ to $100 \mathrm{kHz}$ with $5 \mathrm{mV}$ amplitude at current open circuit voltage.

A two-electrode symmetric supercapacitor cell was assembled to measure the device performances. $\mathrm{MoS}_{2}$ was used as the positive electrode and negative electrode. The negative electrode was prepared by the traditional slurry coating method. The mass loading of electroactive material in symmetric supercapacitor was $0.3 \mathrm{mg}$. The specific capacitances $\left(C_{\mathrm{m}}\right)$ were calculated according to the following equations: $:^{30-32}$
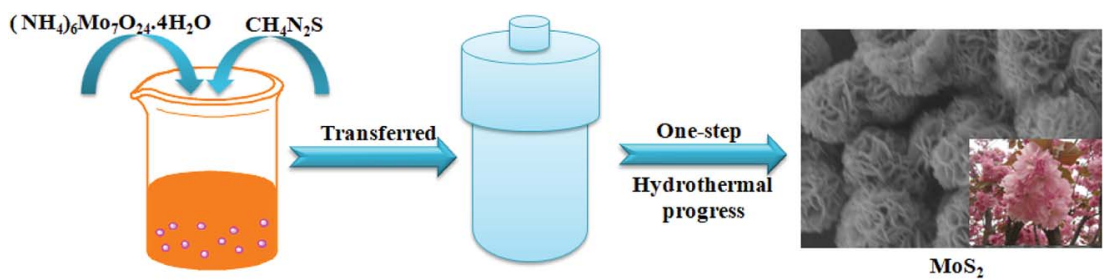

Fig. 1 Schematic of the $\mathrm{MoS}_{2}$ synthesized by hydrothermal method. 


$$
C_{\mathrm{m}}=\frac{I \times \Delta t}{m \times \Delta V}
$$

where $C_{\mathrm{m}}$ is the specific capacitance, $I$ is the current of the charge-discharge, $\Delta t(\mathrm{~s})$ is the discharge time, $\Delta V$ is the voltage window, and $m$ is the mass of active materials.

In the symmetrical supercapacitors, the corresponding power density $(P)$ and energy density $(E)$ were calculated according to the following equations. ${ }^{8}$

$$
\begin{gathered}
E=\frac{C_{\mathrm{m}} \times \Delta V^{2}}{2} \\
P=\frac{E}{\Delta t}
\end{gathered}
$$

\section{Results and discussion}

\subsection{Characterization of $\mathrm{MoS}_{2}$}

Fig. 2 shows the SEM microstructures of the as-prepared $\mathrm{MoS}_{2}$ $8, \mathrm{MoS}_{2}-16$, and $\mathrm{MoS}_{2}-24$. It can be clearly observed from the Fig. 2 that the as-prepared molybdenum disulfide material has a nanoflower-like structure assembled from clear nanoflakes. Different hydrothermal treatment times had a great influence on the size of the molybdenum disulfide nanoflakes and the size of the three-dimensional pore structure. Fig. $2 \mathrm{a}$ and $\mathrm{b}$ show the SEM microstructures of the $\mathrm{MoS}_{2}-8$ at low and high magnifications, respectively. It can be seen that the nanosheets are partially adhered together and contained a small amount of block-like structures, resulting in inconspicuous pore structure. $\mathrm{MoS}_{2}-16$ (Fig. 2c and d) possesses an evenly distributed larger size of nanoflakes, and forms highly open and relatively deep porous nanostructures, making optimal use of the grain surface readily accessible to the liquid electrolyte and providing efficient channels for electron transport. Fig. 2e and f present the low and high magnification SEM image of the $\mathrm{MoS}_{2}-24$ sample. After a $24 \mathrm{~h}$ long hydrothermal process, the nanosheets of $\mathrm{MoS}_{2}$ 24 arranged regularly but too tightly, and some collapsed, resulting in a decrease or disappearance of the pore size in the material, which could degrade the electrochemical performance of the electrode material.

Fig. 3 shows the TEM images for $\mathrm{MoS}_{2}-16$. As shown in Fig. 3a, the interconnected nanoflakes consist of nano-flowers. As seen in the magnified image (Fig. 3b), $\mathrm{MoS}_{2}-16$ nanoflakes are very thin, leading to open and porous three-dimensional structures, which are beneficial to electrolyte access and electron transport during electrochemical reactions. These results are in accordance with the SEM images.

The XRD patterns of $\mathrm{MoS}_{2}-8, \mathrm{MoS}_{2}-16$, and $\mathrm{MoS}_{2}-24$ hybrids are shown in Fig. 4a. The four diffraction peaks at $14.2^{\circ}, 32.5^{\circ}$, $35.8^{\circ}$, and $55.4^{\circ}$ correspond to the (002), (100), (102) and (106) planes of cubic phase $\mathrm{MoS}_{2}$ (JCPDS No. 75-1539). Energydispersive X-ray (EDX) spectroscopy (Fig. 4b) demonstrates the existence of Mo and S elements. The Raman spectrum of the asprepared $\mathrm{MoS}_{2}$ nanoflowers was recorded in this study, as shown in Fig. 4c. At low wave numbers the Raman spectrum of the $\mathrm{MoS}_{2}$ sample showed peaks at 145, 227, 283, 371 and
$403 \mathrm{~cm}^{-1}$, related to the characteristic vibrations of pure metallic phase $\mathrm{MoS}_{2}$. The main peak associated with Mo-Mo metallic vibration is located at $145 \mathrm{~cm}^{-1}$. Two characteristic peaks are observed at 371 and $403 \mathrm{~cm}^{-1}$, which correspond to the $\mathrm{E}_{2 \mathrm{~g}}{ }^{1}$ and $\mathrm{A}_{\mathrm{g}}{ }^{1}$ modes of hexagonal $\mathrm{MoS}_{2}$, and are attributed to the out-of-plane Mo-S phonon mode and the in-plane Mo-S phonon mode, respectively.

The chemical and surface states of the Mo and S elements in the as-prepared $\mathrm{MoS}_{2}-16$ electrodes have been investigated via X-ray photoelectron spectroscopy. The XPS survey spectrum of the $\mathrm{MoS}_{2}$ electrodes is shown in Fig. 5a, which revealed the presence of Mo 3d, Mo 3p, S 2p, C 1s and O 1s states. ${ }^{33}$ The C and $\mathrm{O}$ signals originated from the $\mathrm{CO}_{2}$ and $\mathrm{H}_{2} \mathrm{O}$ impurities, as seen in many XPS analyses. The fine fitted spectrum of Mo 3d is shown in Fig. 5b, which revealed the presence of two major peaks at around 228.5 and $232 \mathrm{eV}$, corresponding to the $\mathrm{Mo}^{4+}$ $3 \mathrm{~d}_{5 / 2}$ and $\mathrm{Mo}^{4+} 3 \mathrm{~d}_{3 / 2}$ states, respectively. Small peaks belonging to $\mathrm{S} 2 \mathrm{~s}$ in the vicinity of $226 \mathrm{eV}$ are also observed. ${ }^{34}$ The fine fitted spectrum of S $2 \mathrm{p}$ (Fig. 5c) indicated the presence of two major peaks at around 161.5 and $162.9 \mathrm{eV}$, which corresponds to the $S 2 p_{3 / 2}$ and $S 2 p_{1 / 2}$ states, respectively. ${ }^{35}$ These studies confirm the formation of $\mathrm{MoS}_{2}$ by the hydrothermal method.

\subsection{Electrochemical and energy storage performance}

Fig. 6a shows the cyclic voltammetry (CV) curves of $\mathrm{MoS}_{2}-8$, $\mathrm{MoS}_{2}-16$ and $\mathrm{MoS}_{2}-24$ at $10 \mathrm{mV} \mathrm{s}^{-1}$ in $1 \mathrm{M} \mathrm{Na}_{2} \mathrm{SO}_{4}$ solution, obtained over the potential range between $-0.3 \mathrm{~V}$ and $0.5 \mathrm{~V}$. In contrast, the CV curve area of the $\mathrm{MoS}_{2}-16$ electrode was larger than the electrode area of $\mathrm{MoS}_{2}-8$ and $\mathrm{MoS}_{2}-24$. Fig. 6b shows the cyclic voltammetry (CV) curves of $\mathrm{MoS}_{2}-16$ at different scan rates. On increasing the scanning speed from $10 \mathrm{mV} \mathrm{s}^{-1}$ to $100 \mathrm{mV} \mathrm{s}^{-1}$, the shape of the CV curve did not change significantly, indicating that $\mathrm{MoS}_{2}-16$ presented better rate performance and small polarization. ${ }^{36,37}$ Galvanostatic chargingdischarging (GCD) technique was also applied to study the electrochemical capacitive properties of $\mathrm{MoS}_{2}-8, \mathrm{MoS}_{2}-16$ and $\mathrm{MoS}_{2}-24$ at a current density of $1 \mathrm{~A} \mathrm{~g}^{-1}$, as shown in Fig. $6 \mathrm{c}$. The longer discharge time of $\mathrm{MoS}_{2}-16$ electrode again confirmed its enhanced capacitance. Fig. 6d shows the galvanostatic chargedischarge curve (GCD) of $\mathrm{MoS}_{2}-16$ at various current densities varying from 1 to $10 \mathrm{~A} \mathrm{~g}^{-1}$, with a potential window range from $-0.3 \mathrm{~V}$ to $0.5 \mathrm{~V}$. Based on eqn (2), for $\mathrm{MoS}_{2}-16$ electrode, at a discharge current of $1 \mathrm{~A} \mathrm{~g}^{-1}$, the specific capacitance reached $518.7 \mathrm{~F} \mathrm{~g}^{-1}$, while at a high discharge current of $10 \mathrm{~A} \mathrm{~g}^{-1}$, the specific capacitance was as high as $275 \mathrm{~F} \mathrm{~g}^{-1}$. Using these GCD curves, the specific capacitances of five electrodes at various current densities were calculated and depicted in Fig. 6e. The calculated specific capacitances of $\mathrm{MoS}_{2}-16$ electrode were calculated to be $518.7,415,363.7,335,318.7$, and $275 \mathrm{~F} \mathrm{~g}^{-1}$ at discharge current densities of $1,2,3,4,5$, and $10 \mathrm{~A} \mathrm{~g}^{-1}$, respectively, which are much higher than those for $\mathrm{MoS}_{2}-8$ and $\mathrm{MoS}_{2}-24$ at the same current densities. Table 1 compares the electrochemical performance of the $\mathrm{MoS}_{2}$ electrode material prepared in this study with that of the $\mathrm{MoS}_{2}$ electrode material reported in the literature. It can be seen that the electrochemical performance of the $\mathrm{MoS}_{2}$ electrode material prepared 

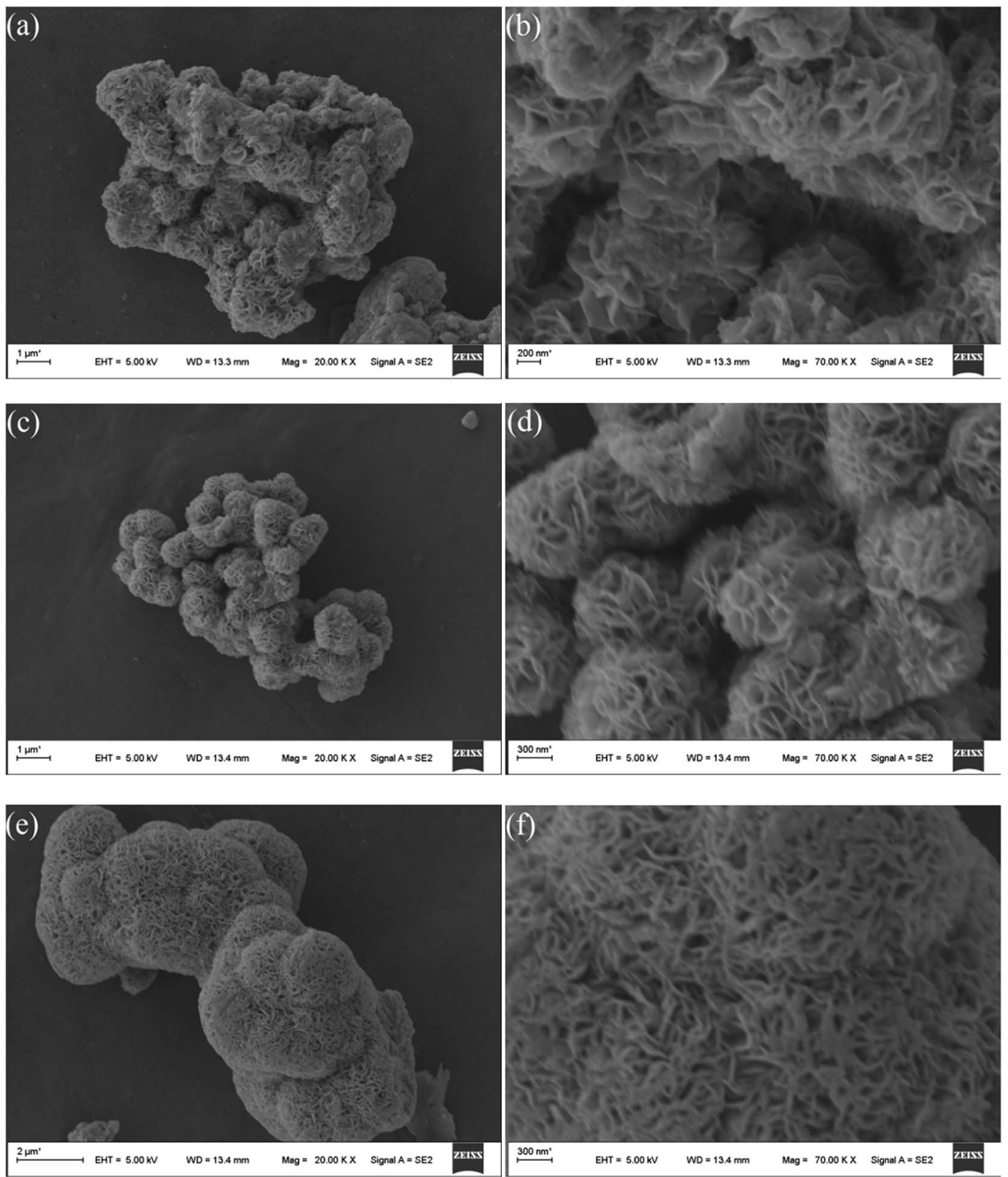

Fig. 2 SEM images of (a and b) $\operatorname{MoS}_{2}-8$, (c and d) $\operatorname{MoS}_{2}-16$, and (e and f) $\operatorname{MoS}_{2}-24$.
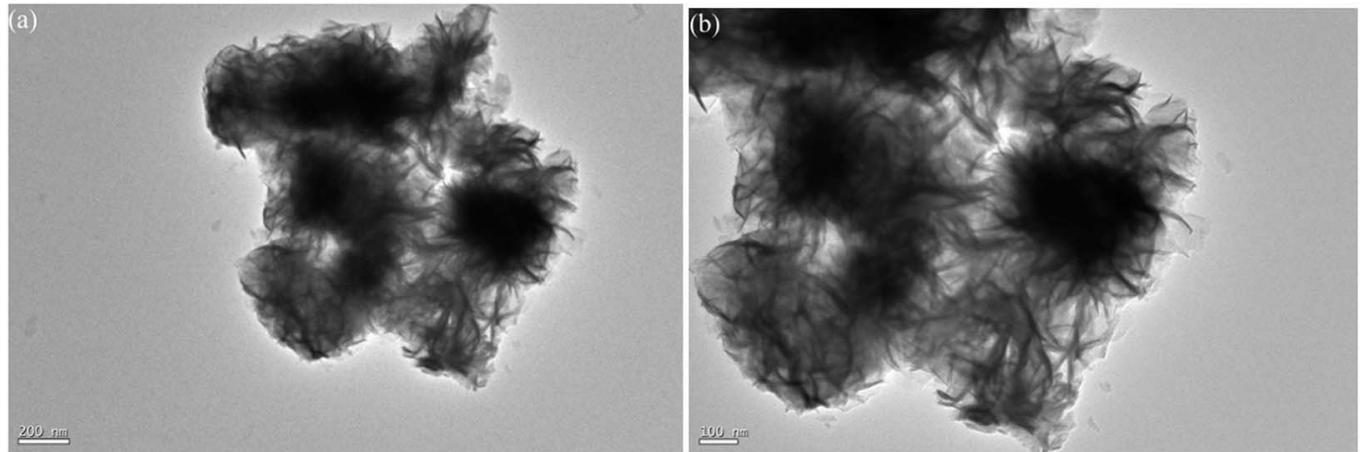

Fig. 3 TEM images of $\mathrm{MoS}_{2}-16$. 

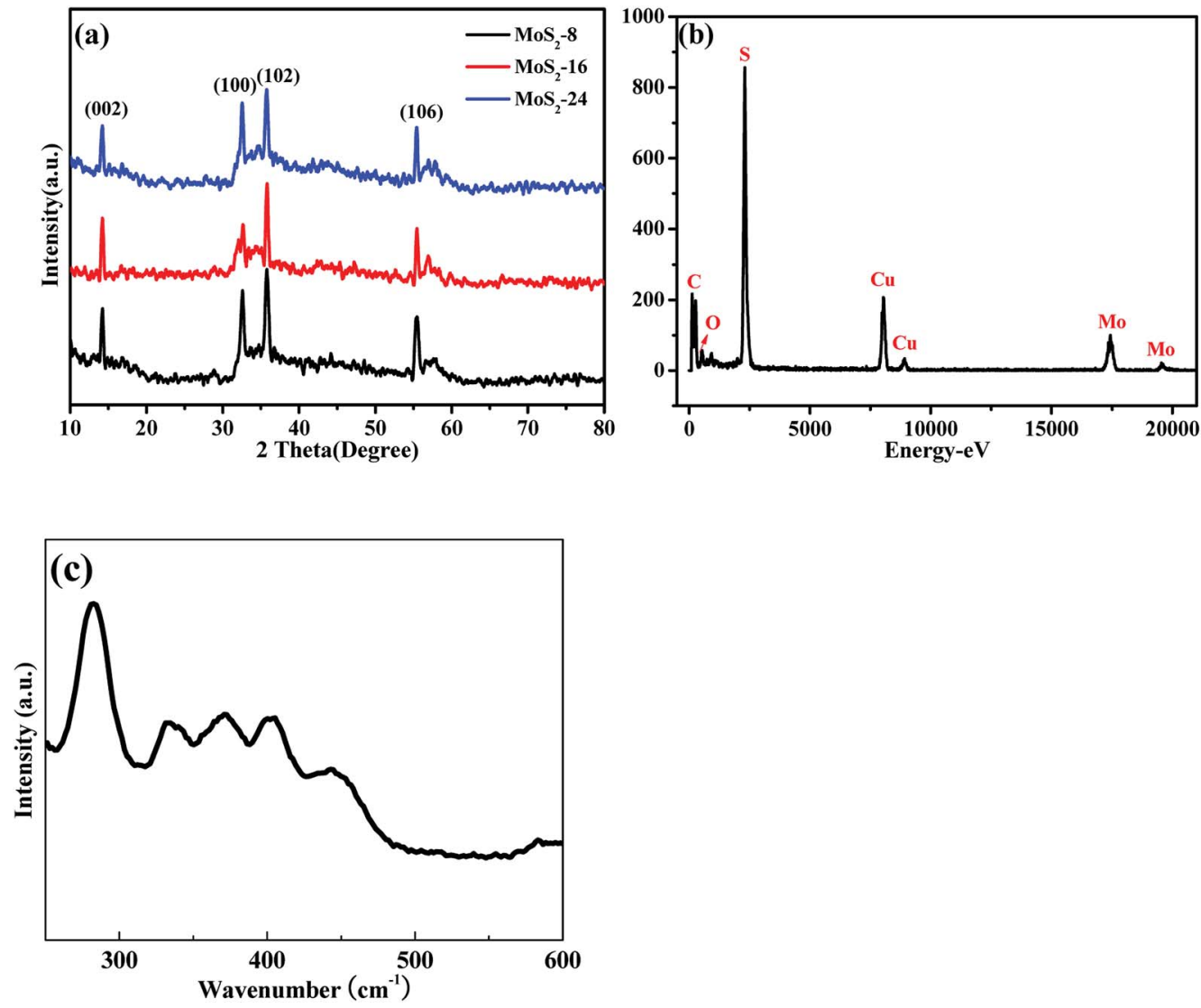

Fig. 4 (a) XRD pattern of the $\mathrm{MoS}_{2}-8, \mathrm{MoS}_{2}-16$, and $\mathrm{MoS}_{2}-24$; (b) EDX spectra of $\mathrm{MoS}_{2}-16$; (c) Raman spectra of $M o S_{2}-16$.

in this experiment is superior. The superior electrochemical behaviors of $\mathrm{MoS}_{2}-16$ nanoflower observed in this study should be partially attributed to its ultrathin and porous features, which can offer even richer electroactive sites, and more efficient and convenient electronic transport.

Electrochemical impedance spectroscopy (EIS) analysis is an important tool to examine the interface resistance of electrode materials for supercapacitors. For an ideal supercapacitor, the Nyquist plot comprises a vertical line, which can be simulated by an equivalent circuit. The semicircle at high frequency region is indicative of interfacial charge transfer resistance. In the equivalent circuit, the series resistance $(R)$ depends on electrolyte resistance and electrode electronic resistance. Nyquist plots based on the radius of the high frequency arc on the real axis are shown in Fig. 6 f. Clearly, the semicircle over the high frequency range of the $\mathrm{MoS}_{2}-16$ electrode is smaller than that of others, indicating the smaller charge-transfer resistance. Furthermore, the slope of the line for $\mathrm{MoS}_{2}-16$ was larger than that of $\mathrm{MoS}_{2}-8$ and $\mathrm{MoS}_{2}-24$, implying a better capacitive behavior and a lower diffusion resistance of ions in the $\mathrm{MoS}_{2}-16$ electrode material. The differences in the electrochemical properties of $\mathrm{MoS}_{2}$ material are mainly due to disparity in the material electrolyte interface properties and electrolyte ion diffusion rates during the charge-discharge processes, which are in good accordance with its abovementioned electrochemical performance.
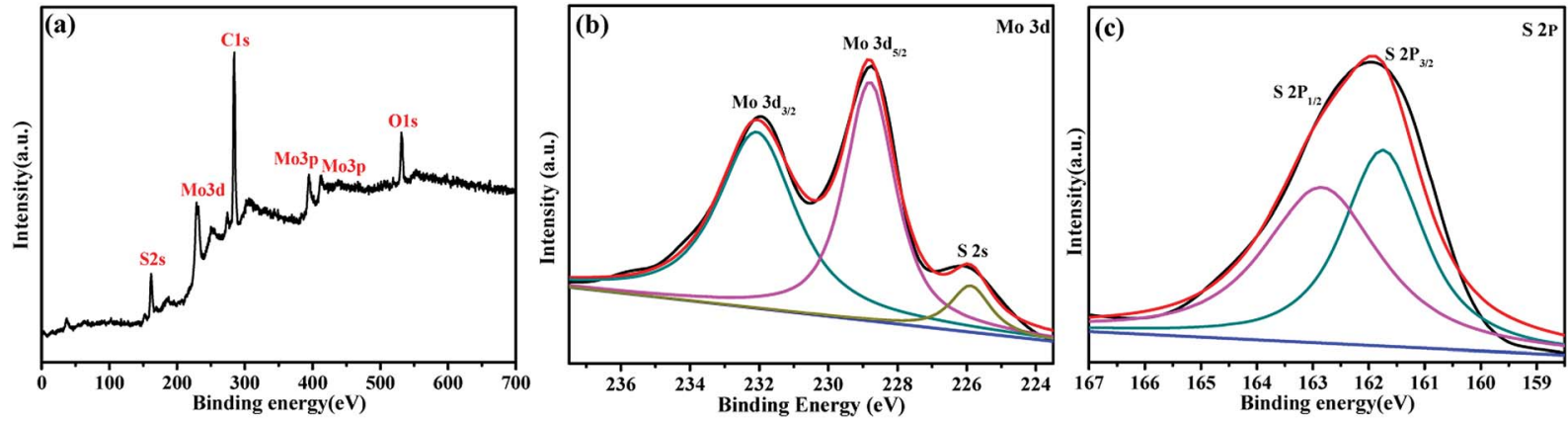

Fig. 5 (a) XPS survey scanning of $M_{o} S_{2}-16$. XPS spectra of (b) Mo $3 d$ and (c) S 2p. 

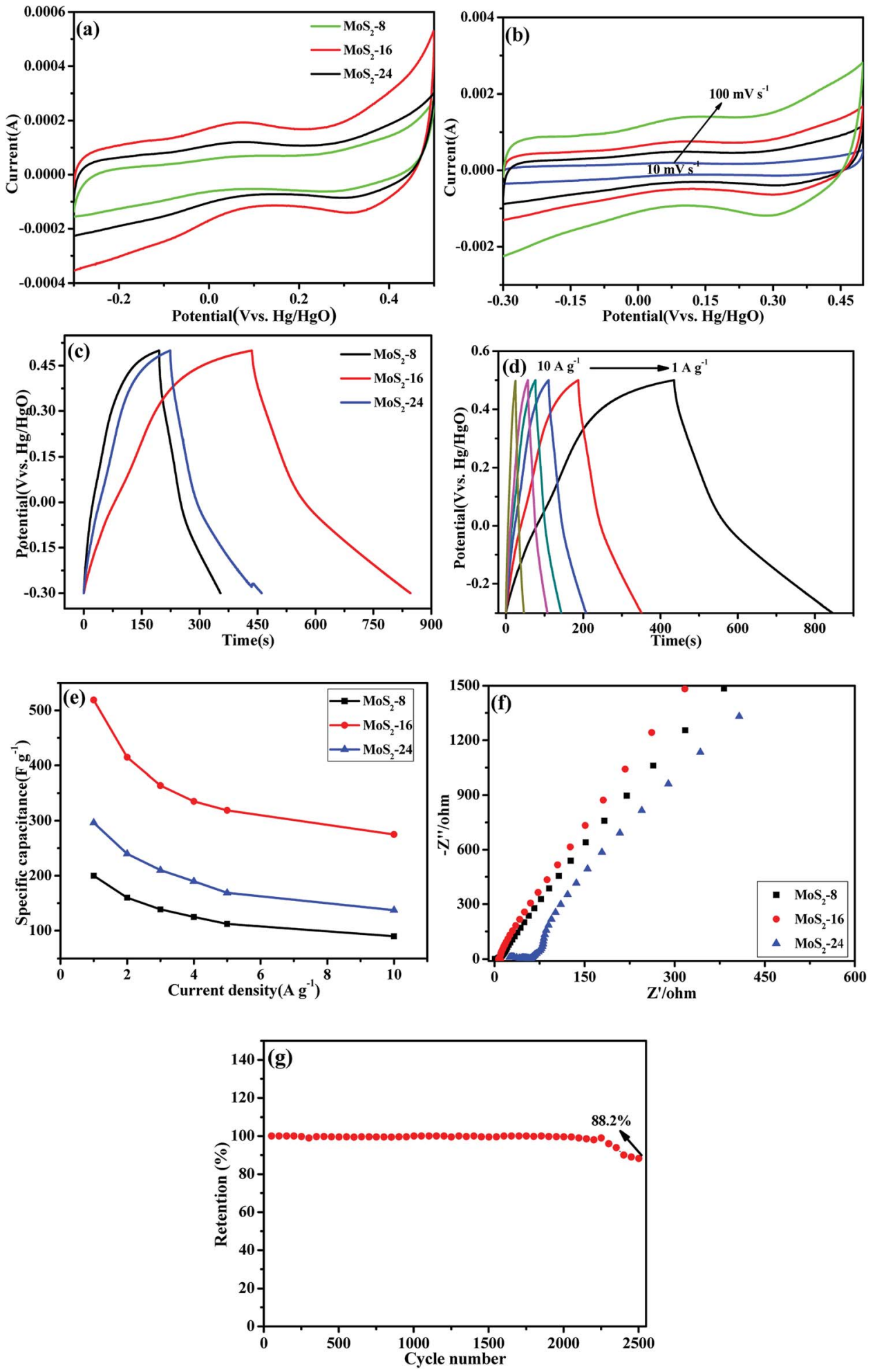

Fig. 6 (a) Cyclic voltammograms of $\mathrm{MoS}_{2}-8, \mathrm{MoS}_{2}-16$, and $\mathrm{MoS}_{2}-24$ at $10 \mathrm{mV} \mathrm{s}{ }^{-1}$. (b) $\mathrm{CV}$ curves of the $\mathrm{MoS}_{2}-16$ electrode at different scan rates. (c) Galvanostatic discharge curves of $\mathrm{MoS}_{2}-8, \mathrm{MoS}_{2}-16$ and $\mathrm{MoS}_{2}-24$ at a current density of $1 \mathrm{~A} \mathrm{~g}^{-1}$. (d) GCD curves of MoS -16 at various current densities. (e) Specific capacitance as a function of the current density of the $\mathrm{MoS}_{2}-8, \mathrm{MoS}_{2}-16$, and $\mathrm{MoS}_{2}-24$. (f) Nyquist plots of MoS -8 , MoS -16 , and $\mathrm{MoS}_{2}-24$ electrodes in the frequency range from $100 \mathrm{kHz}$ to $0.01 \mathrm{~Hz}$. (g) Cycle performance for the $\mathrm{MoS}_{2}-16$ electrodes at a current of $4 \mathrm{~A} \mathrm{~g}^{-1}$.

The cyclic stability of the electrode material is very important for practical supercapacitor applications. The cycling performance of $\mathrm{MoS}_{2}-16$ electrode was tested by 2500 cycles of continuous galvanostatic charge/discharge at the current density of $4 \mathrm{~A} \mathrm{~g}^{-1}$ (Fig. 6g). Although the specific capacitance gradually decreases with the increase of cycle number, there is still $88.2 \%$ retention of the initial capacitance. 
Table 1 Comparison of electrochemical properties of different $\mathrm{MoS}_{2}$ electrode materials

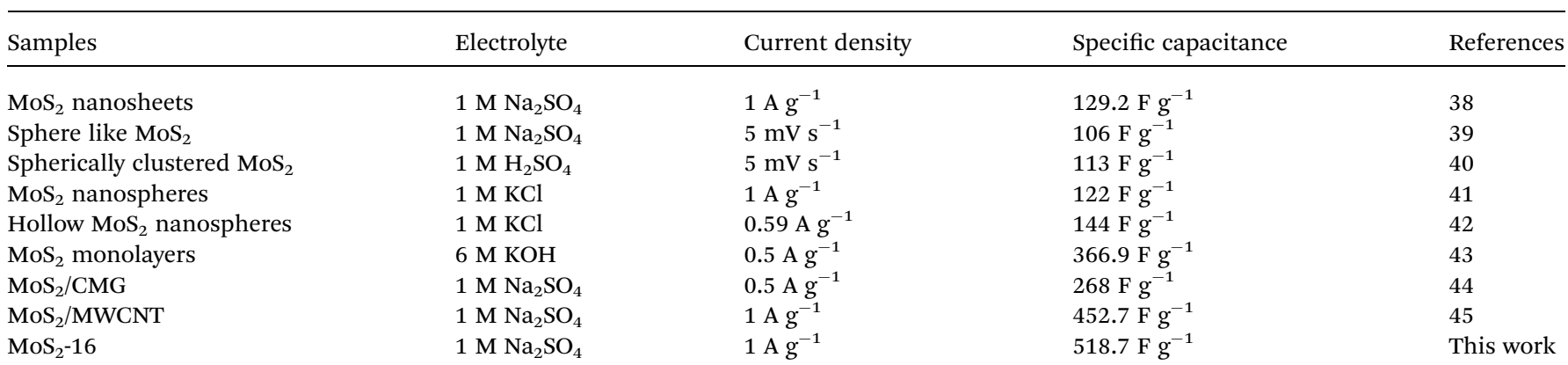
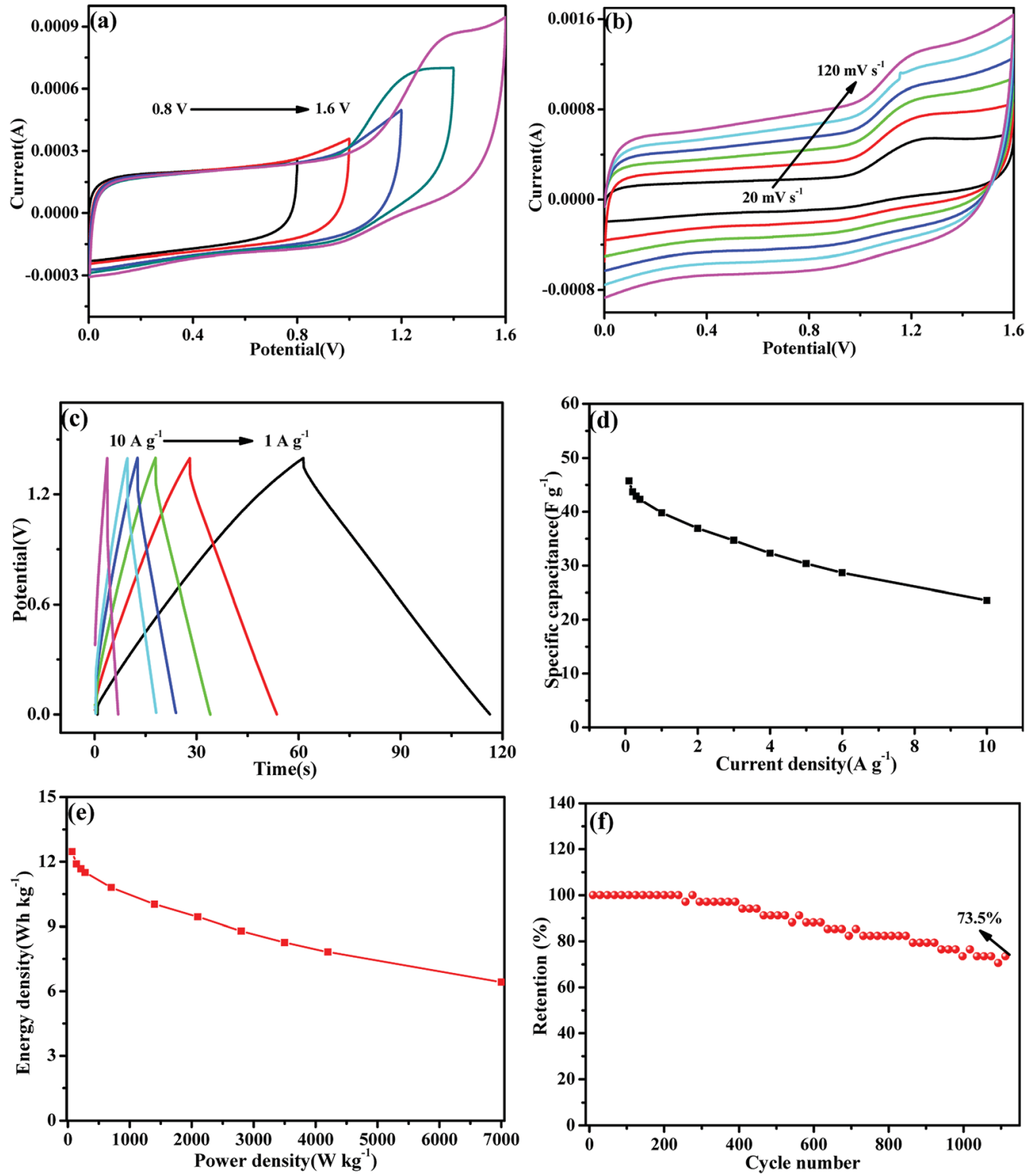

Fig. 7 (a) CV curves of $\mathrm{MoS}_{2}-16 / / \mathrm{MoS}_{2}-16$ measured at different potential windows at a scan rate of $30 \mathrm{mV} \mathrm{s}^{-1}$. (b) $\mathrm{CV}$ curves of the $\mathrm{SC}$ measured at different scan rates ranging from 20 to $120 \mathrm{mV} \mathrm{s}^{-1}$ in potential window of 0 to $1.6 \mathrm{~V}$. (c) Galvanostatic charge/discharge curves of the SC measure at different current densities from 1 to $10 \mathrm{~A} \mathrm{~g}^{-1}$. (d) Specific capacitance as a function of the current density of the symmetric supercapacitor. (e) Ragone plots of the SC. (f) Cycling stability of the SC at $1.6 \mathrm{~A} \mathrm{~g}^{-1}$. 


\subsection{Electrochemical performances of the $\mathrm{MoS}_{2}-16 / / \mathbf{M o S}_{2}-16$} symmetric supercapacitor

To further evaluate the practical application potential of $\mathrm{MoS}_{2}$ 16 electrode, an aqueous SC was first assembled using the $\mathrm{MoS}_{2}-16$ electrode as both positive electrode and negative electrode. Fig. 7a shows a series of CV curves collected at $30 \mathrm{mV}$ $\mathrm{S}^{-1}$ with an operating SC voltage ranging from 0.8 to $1.6 \mathrm{~V}$ to obtain the best operating potential of $\mathrm{MoS}_{2}-16 / / \mathrm{MoS}_{2}-16$. Fig. $7 \mathrm{~b}$ shows typical CV curves for the SC device corresponding to different sweep rates. With the increment of sweep rate from 20 to $120 \mathrm{mV} \mathrm{s}^{-1}$, all the curves presented similar shapes, revealing the splendid high-rate charge-discharge performance of the device. ${ }^{46-48}$ Fig. 7c shows the typical GCD curves of the cells at various current densities with a potential window of $0-1.4 \mathrm{~V}$. During the charge and discharge processes, the charge curve of $\mathrm{MoS}_{2}-16 / / \mathrm{MoS}_{2}-16$ (SSC) and its corresponding discharge curve are observed to be symmetrical, confirming that it has excellent electrochemical reversibility. ${ }^{49}$ The calculated specific capacitance values based on the discharge curves are plotted in Fig. 7d, which are 45.7, 43.7, 42.8, 42.3, 39.8, 36.9 and $23.57 \mathrm{~F}$ $\mathrm{g}^{-1}$ at $0.1,0.2,0.3,0.4,1,2$, and $10 \mathrm{~A} \mathrm{~g}^{-1}$, respectively. Energy density and power density are important parameters to evaluate the performance of symmetric supercapacitors. Fig. 7e presents the Ragone plot of the as-fabricated $\mathrm{MoS}_{2}-16 / / \mathrm{MoS}_{2}-16$ symmetric device, which describes the relationship between the energy and power densities. The supercapacitor device delivered a high energy density of $12.46 \mathrm{~W} \mathrm{~h} \mathrm{~kg}^{-1}$ at the power density of $70 \mathrm{~W} \mathrm{~kg}^{-1}$ and still maintained $6.42 \mathrm{~W} \mathrm{~h} \mathrm{~kg}^{-1}$ at $7 \mathrm{~kW}$ $\mathrm{kg}^{-1}$. Previously reported literature also reported energy storage tests on these similar electrode materials. The as-fabricated selfcharging supercapacitor power cell (SCSPC) delivered a specific capacitance of $18.93 \mathrm{mF} \mathrm{cm}{ }^{-2}$ with a specific energy of $37.90 \mathrm{~mJ}$ $\mathrm{cm}^{-2}$ at a specific power density of $268.91 \mu \mathrm{W} \mathrm{cm}{ }^{-2}$, which were obtained at a constant discharge current of $0.5 \mathrm{~mA} .^{50}$ For the s$\mathrm{MoS}_{2} / \mathrm{CNS}$-based symmetric pseudocapacitor, the equivalent values were $108 \mathrm{~F} \mathrm{~g}^{-1}, 7.4 \mathrm{~W} \mathrm{~h} \mathrm{~kg}{ }^{-1}$ and $3700 \mathrm{~W} \mathrm{~kg}^{-1} .^{51}$ The $\mathrm{MoS}_{2}$-based wire-type solid state supercapacitors (WSCs) device delivered a specific capacitance of $119 \mu \mathrm{F} \mathrm{cm} \mathrm{cm}^{-1}$, and energy density of $8.1 \mathrm{nW} \mathrm{h} \mathrm{cm}{ }^{-1} \cdot{ }^{52}$ Furthermore, the cycling stability of the as-fabricated SC was performed by repeating the GCD test at a current density of $1.6 \mathrm{~A} \mathrm{~g}^{-1}$. The specific capacitance retention of $\mathrm{MoS}_{2}-16 / / \mathrm{MoS}_{2}-16$ was about $73.5 \%$ after 1100 cycles, revealing that this symmetric supercapacitor has eminent cycling stability.

\section{Conclusions}

In summary, we have designed and successfully fabricated flower-shaped $\mathrm{MoS}_{2}$ microspheres assembled from many nanoflakes. The capacitive properties of flower-shaped molybdenum disulfide microspheres as the material of the supercapacitor electrode were studied. The obtained $\mathrm{MoS}_{2}-16$ nanoflower delivered a high specific capacitance of $518.7 \mathrm{~F} \mathrm{~g}^{-1}$ at a current density of $1 \mathrm{~A} \mathrm{~g}^{-1}$, with capacitance retention of $88.2 \%$ after 2500 cycles in alkaline system in a three-electrode cell. To further confirm its practicability, an symmetric supercapacitor was assembled using the $\mathrm{MoS}_{2}-16$ nanoflower as both positive electrode and negative electrode. This supercapacitor delivered a maximum energy density of 12.46 $\mathrm{W} \mathrm{h} \mathrm{kg}^{-1}$ at a power density of $70 \mathrm{~W} \mathrm{~kg}^{-1}$. Even at the highest power density of $7000 \mathrm{~W} \mathrm{~kg}{ }^{-1}$, the $\mathrm{MoS}_{2}-16 / / \mathrm{MoS}_{2}-16$ device still maintained an energy density of $6.42 \mathrm{~W} \mathrm{~h} \mathrm{~kg}^{-1}$. Such outstanding capacitive behaviors imply the $\mathrm{MoS}_{2}-16$ nanoflower as a promising material for energy storage devices.

\section{Conflicts of interest}

There are no conflicts to declare.

\section{Acknowledgements}

We gratefully acknowledge the financial support of this research by the National Natural Science Foundation of China (21065010, 21365019).

\section{References}

1 M. S. Javed, S. Dai, M. Wang, D. Guo, L. Chen, X. Wang, C. Hu and Y. Xi, High performance solid state flexible supercapacitor based on molybdenum sulfide hierarchical nanospheres, J. Power Sources, 2015, 285, 63-69.

2 X. C. Xie, K. J. Huang and X. Wu, Metal-organic framework derived hollow materials for electrochemical energy storage, J. Mater. Chem. A, 2018, 6(16), 6754-6771.

3 Z. B. Zhai, K. J. Huang and X. Wu, Superior mixed Co-Cd selenide nanorods for high performance alkaline batterysupercapacitor hybrid energy storage, Nano Energy, 2018, 47, 89-95.

4 C. Guana, J. Liu, C. Cheng, H. Li, X. Li, W. Zhou, H. Zhang and H. Fan, Hybrid structure of cobalt monoxide nanowire (a) nickel hydroxidenitrate nanoflake aligned on nickel foam for high-rate supercapacitor, Energy Environ. Sci., 2011, 4, 4496-4499.

5 Z. Su, C. Yang, B. Xie, Z. Lin, Z. Zhang, J. Liu, B. Li, F. Kang and C. Wong, Scalable fabrication of $\mathrm{MnO}_{2}$ nanostructure deposited on free-standing $\mathrm{Ni}$ nanocone arrays for ultrathin, flexible, high-performance micro-supercapacitor, Energy Environ. Sci., 2014, 7, 2652-2659.

$6 \mathrm{H}$. Wu, Z. Lou, H. Yang and G. Shen, A flexible spiral-type supercapacitor based on $\mathrm{ZnCo}_{2} \mathrm{O}_{4}$ nanorod electrodes, Nanoscale, 2015, 7, 1921-1926.

7 R. Zou, M. F. Yuen, Z. Zhang, J. Hu and W. Zhang, Threedimensional networked $\mathrm{NiCo}_{2} \mathrm{O}_{4} / \mathrm{MnO}_{2}$ branched nanowire heterostructure arrays on nickel foam with enhanced supercapacitor performance, J. Mater. Chem. A, 2015, 3, 1717-1723.

8 R. Li, S. Wang, Z. Huang, F. Lu and T. He, $\mathrm{NiCo}_{2} \mathrm{~S}_{4} @ \mathrm{Co}(\mathrm{OH})_{2}$ core-shell nanotube arrays in situ grown on Ni foam for high performances asymmetric supercapacitors, J. Power Sources, 2016, 312, 156-164.

9 C. C. Hu, K. H. Chang, M. C. Lin and Y. T. Wu, Design and tailoring of the nanotubular arrayed architecture of 
hydrous $\mathrm{RuO}_{2}$ for next generation supercapacitors, Nano Lett., 2006, 6, 2690-2695.

$10 \mathrm{~J}$. Y. Lin and S. W. Chou, Cathodic deposition of interlaced nanosheet-like cobalt sulfide films for high-performance supercapacitors, RSC Adv., 2013, 3, 2043-2048.

11 Z. Wang, J. Zhu, P. Sun, P. Zhang, Z. Zeng, S. Liang and $\mathrm{X}$. Zhu, Nanostructured $\mathrm{Mn}-\mathrm{Cu}$ binary oxides for supercapacitor, J. Alloys Compd., 2014, 598, 166-170.

12 K. Karthikeyan, A. Antony, M. Y. Sun and K. S. Jae, Plasma assisted synthesis of graphene nanosheets and their supercapacitor applications, Sci. Adv. Mater., 2014, 6, 349353.

$13 \mathrm{H}$. B. $\mathrm{Wu}, \mathrm{H}$. Pang and $\mathrm{X}$. W. Lou, Facile synthesis of mesoporous $\mathrm{Ni}_{0.3} \mathrm{Co}_{2.7} \mathrm{O}_{4}$ hierarchical structures for highperformance supercapacitors, Energy Environ. Sci., 2013, 6, 3619-3626.

14 K. Krishnamoorthy, G. K. Veerasubramanik, S. Radhakrishnan and S. J. Kim, One pot hydrothermal growth of hierarchical nanostructured $\mathrm{Ni}_{3} \mathrm{~S}_{2}$ on $\mathrm{Ni}$ foam for supercapacitor application, Chem. Eng. J., 2014, 251, 116-122.

15 K. Krishnamoorthy, G. K. Veerasubramani, S. Radhakrishnan and S. J. Kim, Supercapacitive properties of hydrothermally synthesized sphere like $\mathrm{MoS}_{2}$ nanostructures, Mater. Res. Bull., 2014, 50, 499-502.

16 W. J. Zhang and K. J. Huang, A review of recent progress in molybdenum disulfide-based supercapacitors and batteries, Inorg. Chem. Front., 2017, 4(10), 1602-1620.

17 K. Krishnamoorthy, G. K. Veerasubramani, P. Pazhamalai and S. J. Kim, Designing two dimensional nanoarchitectured $\mathrm{MoS}_{2}$ sheets grown on Mo foil as a binder free electrode for supercapacitors, Electrochim. Acta, 2016, 190, 305-312.

$18 \mathrm{X}$. Hu, W. Zhang, X. Liu, Y. Meia and Y. Huang, Nanostructured Mo-based electrode materials for electrochemical energy storage, Chem. Soc. Rev., 2015, 44, 2376-2404.

19 L. Wang, Z. Xu, W. Wang and X. Bai, Atomic mechanism of dynamic electrochemical lithiation processes of $\mathrm{MoS}_{2}$ nanosheets, J. Am. Chem. Soc., 2014, 136, 6693-6697.

20 X. Zhao, J. Sui, F. Li, H. Fang, H. Wang, J. Li, W. Cai and G. Cao, Lamellar $\mathrm{MoSe}_{2}$ nanosheets embedded with $\mathrm{MoO}_{2}$ nanoparticles: novel hybrid nanostructures promoted excellent performances for lithium ion batteries, Nanoscale, 2016, 8, 17902-17910.

21 Y. Shi, W. Zhou, A. Y. Lu, W. Fang, Y. H. Lee, A. L. Hsu, S. M. Kim, K. K. Kim, H. Y. Yang, L. J. Li, J. C. Idrobo and J. K. van der, Waals epitaxy of $\mathrm{MoS}_{2}$ layers using graphene as growth templates, Nano Lett., 2012, 12, 2784-2791.

22 Y. H. Lee, X. Q. Zhang, W. Zhang, M. T. Chang, C. T. Lin, K. D. Chang, Y. C. Yu, J. W. Wang, C. S. Chang, L. J. Li and T. W. Lin, Synthesis of large-area $\mathrm{MoS}_{2}$ atomic layers with chemical vapor deposition, Adv. Mater., 2012, 24, 2320-2325.

23 M. Acerce, D. Voiry and M. Chhowalla, Metallic 1T phase $\mathrm{MoS}_{2}$ nanosheets as supercapacitor electrode materials, Nat. Nanotechnol., 2015, 10, 313-318.
24 K. Bindumadhavan, S. K. Srivastava and S. Mahanty, $\operatorname{MoS}_{2}-$ MWCNT hybrids as a superior anode in lithium-ion batteries, Chem. Commun., 2013, 49, 1823-1825.

25 J. M. Soon and K. P. Loh, Electrochemical double-layer capacitance of $\mathrm{MoS}_{2}$ nanowall films, Electrochem. SolidState Lett., 2007, 10, A250-A254.

26 G. Ma, H. Peng, J. Mu, H. Huang, X. Zhou and Z. Lei, In situ intercalative polymerization of pyrrole in graphene analogue of $\mathrm{MoS}_{2}$ as advanced electrode material in supercapacitor, $J$. Power Sources, 2013, 229, 72-78.

27 L. Cao, S. Yang, W. Gao, Z. Liu, Y. Gong, L. Ma, G. Shi, S. Lei, Y. Zhang, S. Zhang, R. Vajtai and P. M. Ajayan, Direct laserpatterned micro-supercapacitors from paintable $\mathrm{MoS}_{2}$ films, Small, 2013, 9, 2905-2910.

28 K. J. Huang, L. Wang, Y. J. Liu, H. B. Wang, Y. M. Liu and L. L. Wang, Synthesis of polyaniline/2-dimensional graphene analog $\mathrm{MoS}_{2}$ composites for high-performance supercapacitor, Electrochim. Acta, 2013, 109, 587-594.

29 M. Sarno, S. Galvagno, R. Piscitelli, S. Portofino and P. Ciambelli, Supercapacitor Electrodes Made of Exhausted Activated Carbon-Derived SiC Nanoparticles Coated by Graphene, Ind. Eng. Chem. Res., 2016, 20, 6025-6035.

30 X. Wang, Y. Xiao, D. Su, L. Zhou, S. Wu, L. Han, S. Fang and S. Cao, High-quality Porous Cobalt Monoxide Nanowires@Ultrathin Manganese dioxide Sheets CoreShell Nanowire Arrays on Ni Foam for High-Performance Supercapacitor, Electrochim. Acta, 2016, 194, 377-384.

31 P. Yang and W. Main, Flexible solid-state electrochemical supercapacitors, Nano Energy, 2014, 8, 274-290.

32 L. L. Xing, K. J. Huang, S. X. Cao and H. Pang, Chestnut shelllike $\mathrm{Li}_{4} \mathrm{Ti}_{5} \mathrm{O}_{12}$ hollow spheres for high-performance aqueous asymmetric supercapacitors, Chem. Eng. J., 2018, 332, 253259.

33 Z. Pu, Q. Liu, A. M. Asiri, Y. Luo, X. Sun and Y. He, 3D macroporous $\mathrm{MoS}_{2}$ thin film: in situ hydrothermal preparation and application as a highly active hydrogen evolution electrocatalyst at all $\mathrm{pH}$ values, Electrochim. Acta, 2015, 168, 133-138.

34 J. Shi, Y. Yang, Y. Zhang, D. Ma, W. Wei, Q. Ji, Y. Zhang, X. Song, T. Gao, C. Li, X. Bao, Z. Liu, Q. Fu and Y. Zhang, Monolayer $\mathrm{MoS}_{2}$ growth on $\mathrm{Au}$ foils and on-site domain boundary imaging, Adv. Funct. Mater., 2015, 25, 842-849.

35 Z. Lu, H. Zhang, W. Zhu, X. Yu, Y. Kuang, Z. Chang, X. Lei and X. Sun, In situ fabrication of porous $\mathrm{MoS}_{2}$ thin-films as high-performance catalysts for electrochemical hydrogen evolution, Chem. Commun., 2013, 49, 7516-7518.

36 C. Yuan, J. Li, L. Hou, X. Zhang, L. Shen and X. W. Lou, Ultrathin mesoporous $\mathrm{NiCo}_{2} \mathrm{O}_{4}$ nanosheets supported on Ni foam as advanced electrodes for supercapacitors, Adv. Funct. Mater., 2012, 22, 4592-4597.

37 J. J. Wei, H. Liu, K. Niki, E. Margoliash and D. H. Waldeck, Probing electron tunneling pathways: electrochemical study of rat heart cytochrome $\mathrm{c}$ and its mutant on pyridine-terminated SAMs, J. Phys. Chem. B, 2004, 108, 16912-16917.

38 K. J. Huang, J. Z. Zhang, G. W Shi and Y. M. Liu, Hydrothermal synthesis of molybdenum disulfide 
nanosheets as supercapacitors electrode material, Electrochim. Acta, 2014, 132, 397-403.

39 K. Karthikeyan, G. K. Veerasubramani, S. Radhakrishnan and S. J. Kim, Supercapacitive properties of hydrothermally synthesized sphere like $\mathrm{MoS}_{2}$ nanostructures, Mater. Res. Bull., 2014, 50, 499-502.

40 P. Ilanchezhiyan, G. Mohan Kumar and T. W. Kang, Electrochemical studies of spherically clustered $\mathrm{MoS}_{2}$ nanostructures for electrode applications, J. Alloys Compd., 2015, 634, 104-108.

41 X. Zhou, B. Xu, Z. Lin, D. Shu and L. Ma, Hydrothermal synthesis of flower-like $\mathrm{MoS}_{2}$ nanospheres for electrochemical supercapacitors, J. Nanosci. Nanotechnol., 2014, 14, 7250-7254.

42 L. Wang, Y. Ma, M. Yang and Y. Qi, Hierarchical hollow $\mathrm{MoS}_{2}$ nanospheres with enhanced electrochemical properties used as an electrode in supercapacitor, Electrochim. Acta, 2015, 186, 391-396.

43 L. Jiang, S. Zhang, S. A. Kulinich, X. Song, J. Zhu, X. Wang and $\mathrm{H}$. Zeng, Optimizing hybridization of $1 \mathrm{~T}$ and $2 \mathrm{H}$ phases in $\mathrm{MoS}_{2}$ monolayers to improve capacitances of supercapacitors, Mater. Res. Lett., 2015, 3, 177-183.

44 M. H. Yang, J. M. Jeong, Y. S. Huh and B. G. Choi, Highperformance supercapacitor based on three-dimensional $\mathrm{MoS}_{2}$ /graphene aerogel composites, Compos. Sci. Technol., 2015, 121, 123-128.

45 K. J. Huang, L. Wang, J. Z. Zhang, L. L. Wang and Y. P. Mo, One-step preparation of layered molybdenum disulfide/ multi-walled carbon nanotube composites for enhanced performance supercapacitor, Energy, 2014, 67, 234-240.

46 S. Liu, K. S. Hui and K. N. Hui, Flower-like copper cobaltite nanosheets on graphite paper as high-performance supercapacitor electrodes and enzymeless glucose sensors, ACS Appl. Mater. Interfaces, 2016, 8, 3258-3267.

47 X. Pan, G. Ren, M. N. F. Hoque, S. Bayne, K. Zhu and Z. Fan, Fast supercapacitors based on graphene-bridged $\mathrm{V}_{2} \mathrm{O}_{3} / \mathrm{VO}_{\mathrm{x}}$ core-shell nanostructure electrodes with a power density of $1 \mathrm{MW} \mathrm{kg}^{-1}$, Adv. Mater. Interfaces, 2014, 1, 1400398.

48 F. Wang, G. Li, J. Zheng, J. Ma, C. Yang and Q. Wang, Microwave synthesis of three-dimensional nickel cobalt sulfide nanosheets grown on nickel foam for highperformance asymmetric supercapacitors, J. Colloid Interface Sci., 2018, 516, 48-56.

49 S. Cheng, T. Shi, Y. Huang, X. Tao, J. Li, C. Cheng, G. Liao and Z. Tang, Rational design of nickel cobalt sulfide/oxide core-shell nanocolumn arrays for high-performance flexible all-solid-state asymmetric supercapacitors, Ceram. Int., 2017, 43, 2155-2164.

50 P. Parthiban, K. Krishnamoorthy, V. K. Mariappan, S. Sahoo, S. Manoharan and S. Kim, A high efficacy self-charging $\mathrm{MoSe}_{2}$ solid-state supercapacitor using electrospun nanofibrous piezoelectric separator with ionogel electrolyte, Adv. Mater. Interfaces, 2018, 1800055.

51 T. N. Y. Khawula, K. Raju, P. J. Franklyn, I. Sigalas and K. I. Ozoemena, Symmetric pseudocapacitors based on molybdenum disulfide $\left(\mathrm{MoS}_{2}\right)$-modified carbon nanospheres: correlating physicochemistry and synergistic interaction on energy storage, J. Mater. Chem. A, 2016, 4(17), 6411-6425.

52 K. Karthikeyan, P. Pazhamalai, G. K. Veerasubramani and S. J. Kim, Mechanically delaminated few layered $\mathrm{MoS}_{2}$ nanosheets based high performance wire type solid-state symmetric supercapacitors, J. Power Sources, 2016, 321, 112-119. 